\title{
A Comparison of Quality of Life in Elderly Patients with Intermittent Claudication and Chronic Limb- Threatening Ischemia
}

Citation for published version (APA):

Roijers, J. P., van den Houten, M. M., Hopmans, N. J., Vriens, P. W. H. E., Willigendael, E. M., Lodder, P., de Vries, J., Teijink, J. A., \& van der Laan, L. (2020). A Comparison of Quality of Life in Elderly Patients with Intermittent Claudication and Chronic Limb-Threatening Ischemia. Annals of Vascular Surgery, 69, 285-291. https://doi.org/10.1016/j.avsg.2020.05.048

Document status and date:

Published: 01/11/2020

DOI:

10.1016/j.avsg.2020.05.048

Document Version:

Publisher's PDF, also known as Version of record

\section{Document license:}

Taverne

Please check the document version of this publication:

- A submitted manuscript is the version of the article upon submission and before peer-review. There can be important differences between the submitted version and the official published version of record.

People interested in the research are advised to contact the author for the final version of the publication, or visit the DOI to the publisher's website.

- The final author version and the galley proof are versions of the publication after peer review.

- The final published version features the final layout of the paper including the volume, issue and page numbers.

Link to publication

\footnotetext{
General rights rights.

- You may freely distribute the URL identifying the publication in the public portal. please follow below link for the End User Agreement:

www.umlib.nl/taverne-license

Take down policy

If you believe that this document breaches copyright please contact us at:

repository@maastrichtuniversity.nl

providing details and we will investigate your claim.
}

Copyright and moral rights for the publications made accessible in the public portal are retained by the authors and/or other copyright owners and it is a condition of accessing publications that users recognise and abide by the legal requirements associated with these

- Users may download and print one copy of any publication from the public portal for the purpose of private study or research.

- You may not further distribute the material or use it for any profit-making activity or commercial gain

If the publication is distributed under the terms of Article 25fa of the Dutch Copyright Act, indicated by the "Taverne" license above, 


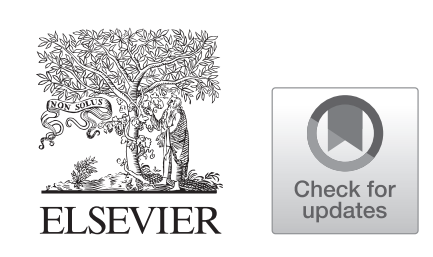

\title{
A Comparison of Quality of Life in Elderly Patients with Intermittent Claudication and Chronic Limb-Threatening Ischemia
}

\author{
Joost P. Roijers, ${ }^{1}$ Marijn M. van den Houten, ${ }^{2}$ Niels J. Hopmans, ${ }^{1}$ Patrick W.H.E. Vriens, ${ }^{3}$ \\ Edith M. Willigendael, ${ }^{4}$ Paul Lodder, ${ }^{5,6}$ Jolanda de Vries, ${ }^{3}$ Joep A. Teijink, ${ }^{2,7}$ and \\ Lijckle van der Laan, ${ }^{1,8}$ Tilburg, the Netherlands, and Enschede, the Netherlands, and KU \\ Leuven, Belgium
}

\begin{abstract}
Background: Intermittent claudication (IC) and chronic limb-threatening ischemia (CLTI) are both associated with a decreased health status and possibly quality of life (QOL). A better understanding of the differences in QOL between patients with IC and CLTI could be of additional value in shared decision-making. The aim of this study was to compare the QOL at baseline between patients with IC and patients with CLTI.

Methods: The study population was based on 2 study cohorts, 1 cohort consisted of patients with IC (ELECT registry) and the other cohort of patients with CLTI (KOP-study). Patients with an age of $\geq 70$ years were included. QOL at baseline was measured by the WHOQOL-BREF questionnaire. Nonresponders were excluded from data analyses. Student's $t$-tests and analysis of covariance (ANCOVA) analyses were used to compare QOL between the 2 groups. Outcomes of the ANCOVA analyses were expressed as estimated marginal means.

Results: In total, 308 patients were included, 115 patients with IC and 193 patients with CLTI. Patients with CLTI were older (median age 80 years vs. 75 years, $P<0.001$ ) and had more comorbidities. Patients with IC had a statistically significant higher QOL regarding physical health (mean 13.7 [standard deviation (SD) 2.3] vs. 10.8 [SD 2.8], $P<0.001$ ), psychological health (mean 15.3 [SD 2.1] vs. 14.1 [SD 2.4], $P<0.001$ ), environment (mean 16.3 [SD 2.4] vs. 15.5 [SD 2.0], $P<0.002$ ), and the overall domain (mean 3.5 [SD 0.7] vs. 3.1 [SD 0.9], $P<0.001$ ). After correcting for the confounding effect of age and sex, patients with IC still had a statistically significant higher QOL in the physical, psychological, environment, and overall domain.

Conclusions: Patients with IC had a significantly higher QOL in the physical, psychological, environment, and overall domains of the WHOQOL-BREF questionnaire compared with patients with CLTI. This underlines the importance of strategies that reduce disease progression as disease progression is associated with a decrease in QOL.
\end{abstract}

Conflict of interest: The author(s) declared no potential conflicts of interest with respect to the research, authorship, and/or publication of this article.

Funding: This research did not receive any specific grant from funding agencies in the public, commercial, or not-for-profit sectors.

${ }^{1}$ Department of Surgery, Amphia Hospital, Breda, the Netherlands.

${ }^{2}$ Department of Vascular Surgery, Catharina Hospital, Eindhoven, the Netherlands.

${ }^{3}$ Dept. of Vascular Surgery, Elisabeth Twee Steden Hospital, Tilburg, the Netherlands.

${ }^{4}$ Dept. of Vascular Surgery, Medical Spectrum Twente, Enschede, the Netherlands.

${ }^{5}$ Department of Medical and Clinical Psychology, Tilburg University, Tilburg, the Netherlands.
${ }^{6}$ Department of Methodology and Statistics, Tilburg University, Tilburg, the Netherlands.

${ }^{7}$ CAPHRI School for Public Health and Primary Care, Faculty of Health, Medicine and Life Sciences, Maastricht University, Maastricht, the Netherlands.

${ }^{8}$ Department of Cardiovascular Science, KU Leuven, Belgium.

Correspondence to: Joost P. Roijers, Department of Surgery, Amphia Hospital Breda, Molengracht 21, 4818 CK Breda PO Box 90158, 4800 RK Breda, the Netherlands; E-mail: joostroijers@hotmail.com

Ann Vasc Surg 2020; 69: 285-291

https://doi.org/10.1016/j.avsg.2020.05.048

(C) 2020 Elsevier Inc. All rights reserved.

Manuscript received: April 11, 2020; manuscript accepted: May 14, 2020; published online: 3 June 2020 


\section{INTRODUCTION}

The World Health Organization (WHO) defines quality of life (QOL) as "an individual's perception of their position in life in the context of the culture and value systems in which they live and in relation to their goals, expectations, standards, and concerns. It is a broad ranging concept affected in a complex way by the person's physical health, psychological state, personal beliefs, social relationships, and their relationship to salient features of their environment."' Health status (HS) or healthrelated QOL, on the other hand, uses a strictly functional approach to measure physical, psychological, and social functioning.

HS in patients with peripheral arterial disease (PAD) is mainly affected because of a decreased physical capacity. ${ }^{2}$ Classically, there are 2 distinct forms of PAD: intermittent claudication (IC) and chronic limb-threatening ischemia (CLTI). Treatment strategies in patients with IC and CLTI may differ from one another. For example, supervised exercise therapy that results in an improved walking distance results in improved HS for a patient with IC. ${ }^{3-5}$ Whereas, adequate pain management may improve HS for a patient with CLTI. ${ }^{6}$

Rather than outcomes that assess the success of treatment by its effect on technical measures or symptomatology (e.g., walking distance, patency, or limb salvage), the perception of a patient's treatment experience is becoming increasingly important. Nowadays, the incorporation of patientreported outcomes as a clinical outcome measure is therefore strongly recommended by the recently published guideline for CLTI. $^{7}$

In contrast to HS, the WHOQOL-BREF questionnaire measures QOL. It assesses a patient's subjective appraisal of their satisfaction with various domains of health. ${ }^{8}$ To do so, this questionnaire assesses a range of domains of health: physical health, psychological health, socials relationships, environment, and overall health. HS uses a functional approach to measure functioning ('Are you able to climb the stairs'?). On the other hand in QOL, the emphasis is laid on evaluating the patients feelings about functioning ('How satisfied are you about your ability to climb the stairs?'). Several studies have described QOL-related outcomes in separate IC and CLTI cohorts. ${ }^{9-13}$ One study compared HS between CLTI and milder forms of PAD by using the Short Form 36 and the EuroQol-5D questionnaires. ${ }^{11}$ A diminished HS was observed for patients with CLTI. Thus, while a diminished general QOL for CLTI patients as compared with IC patients may be expected, it has not been confirmed.
Furthermore, insight in which of the various domains of health are affected in CLTI and CI may be of particular interest.

A better understanding of the differences in QOL between patients with IC and CLTI could be of additional value in the shared decision making process. The aim of this study was to compare the QOL at baseline between patients with IC and patients with CLTI using the WHOQOL-BREF questionnaire.

\section{MATERIAL AND METHODS}

\section{Patient Population}

The study population was based on 2 individual study cohorts, 1 cohort consisted of patients with IC and the other cohort of patients with CLTI.

Patients with IC were part of the ELECT registry, and the study protocol of this registry has been previously published. ${ }^{14}$ In summary, one goal of this registry was to obtain data on QOL at different time intervals in patients with IC that underwent supervised exercise therapy (SET). Inclusion criteria were patients with IC that were candidate for SET as a primary treatment. Exclusion criteria were patients with CLTI, a vascular intervention as primary treatment, prior SET or revascularization less than 12 months ago and patients with neurogenic/ venous/orthopedic claudication. Patients from the ELECT registry with an age $\geq 70$ years were eligible for inclusion.

Patients with CLTI were part of the KOP-study. The methods have been previously published. ${ }^{10}$ The KOP-study served to assess QOL at different time intervals in patients with CLTI that underwent surgical, endovascular, or conservative treatment. Inclusion criteria were patients with a diagnosis of CLTI with an age $\geq 70$ years. Exclusion criteria were patients with cognitive impairment, a recent diagnosis of a malignancy, and a prior major lower limb amputation.

Informed consent was obtained and signed for each individual patient in both study cohorts. A formal written waiver for ethical approval was not required as was confirmed by the institutional review board (AMOA).

\section{Data Collection}

Data on age, gender, smoking status, medical history, and prior vascular surgery were obtained from the medical charts. Medical history was put into the following categories: history of cardiac disease (myocardial infarction, atrial fibrillation, history of heart failure, valvular disease, coronary 
Table I. Baseline characteristics of both cohorts

\begin{tabular}{llcrrr}
\hline Variable & IC $(\mathrm{n}=115)$ & Missing & CLTI $(n=193)$ & Missing & $P$-value \\
\hline Age, years (range) & $75(70-93)$ & 4 & $80(70-94)$ & 0 & $<0.001$ \\
Gender, male (\%) & $66(57.4)$ & 1 & $108(56)$ & 0 & 0.812 \\
Active smoking (\%) & $30(26.1)$ & 15 & $45(23.3)$ & 4 & 0.449 \\
Diabetes mellitus (\%) & $36(31.3)$ & 0 & $91(47.2)$ & 0 & 0.008 \\
Hypertension (\%) & $84(73)$ & 0 & $161(83.4)$ & 0 & 0.040 \\
Hypercholesterolemia (\%) & $74(64.3)$ & 0 & $137(71)$ & 0.254 \\
Renal impairment (\%) & $18(15.7)$ & 2 & $108(56)$ & 0 & $<0.001$ \\
Cardiac History (\%) & $37(32.2)$ & 0 & $133(68.9)$ & 0 & $<0.001$ \\
Pulmonary History (\%) & $28(24.3)$ & 0 & $109(56.5)$ & 3 & $<0.001$ \\
Cerebrovascular History (\%) & $16(13.9)$ & 0 & $62(32.1)$ & 0 & $<0.001$ \\
History of PTA/stent (\%) & $23(20)$ & 0 & $51(26.4)$ & 0 & 0.217 \\
History of Thromboendarterectomy (\%) & $2(1.7)$ & 0 & $12(6.2)$ & 0 & 0.090 \\
History of Bypass Surgery (\%) & $5(4.3)$ & 0 & $31(16.1)$ & 0 & 0.002 \\
\hline
\end{tabular}

PTA, percutaneous transluminal angioplasty.

artery bypass graft, or percutaneous coronary intervention), history of pulmonary disease (chronic obstructive pulmonary disease, asthma, obstructive sleep apnea syndrome), history of renal impairment (eGFR $<60 \mathrm{ml} / \mathrm{min} / 1.73 \mathrm{~m}^{2}$ ), history of cerebrovascular disease (cerebrovascular incident or transient ischemic attack), and a history of diabetes mellitus, hypercholesterolemia, and hypertension.

\section{Quality of Life}

The WHOQOL-BREF questionnaire was used to measure QOL at baseline. This questionnaire consists of 26 items with a 5-point Likert type response scale. The questions are divided into 4 individual domains: physical health, psychological health, social relationships, and environment. Additionally, answers to 2 questions are summed to retrieve an overall QOL score. ${ }^{8}$

\section{Outcome Measures}

The primary end point was QOL at baseline as measured with the WHOQOL-BREF questionnaire. Secondarily, the various subdomains of the WHOQOL-BREF were compared between both cohorts.

\section{Statistical Analysis}

Categorical variables were presented as numbers with percentages, continuous variables as medians with range, normally distributed continuous variables as means with standard deviation (SD). Baseline characteristics were compared using a Pearson's chi-squared test or Fisher's exact test for categorical variables and the Mann-Whitney $U$-test for continuous variables. The Student's $t$-test was used to calculate differences in QOL between the
IC and CLTI group. In a subgroup analysis of patients with CLTI, the QOL of patients with rest pain (Fontaine III) was compared with patients with ulcers/ gangrene (Fontaine IV).

To calculate the QOL domains, patients had to have at least 5 answers in the physical domain, 4 answers in the psychological domain, 2 answers in the social relationships domain, 6 answers in the environment domain, and 2 answers in the overall domain. Mean imputation was used in case of missing answers. Nonresponders were excluded from data analysis.

Differences in QOL between the 2 groups were also analyzed by means of analysis of covariance (ANCOVA) analyses. The covariates age and sex were added to the model as possible confounders. In a secondary ANCOVA analysis, age, sex, diabetes, hypertension, renal impairment, cardiac history, pulmonary history, cerebrovascular history, and history of bypass surgery were added as possible confounders based on the results of Table I. Outcomes of the ANCOVA analyses were expressed as estimated marginal means with associated 95\% confidence intervals (CIs). The estimated marginal mean displays the mean difference in QOL between the IC and CLTI group given a similar age and sex in both groups. Cohen's d values with corresponding 95\% CIs were calculated to assess the effect sizes of the differences in QOL between the 2 groups.

A $p$ value $<0.05$ was considered statistically significant in all analyses. Statistical analyses were performed using SPSS, version 25.

\section{RESULTS}

In total, 308 patients were included in the study population. Of these, 115 patients had IC and 193 


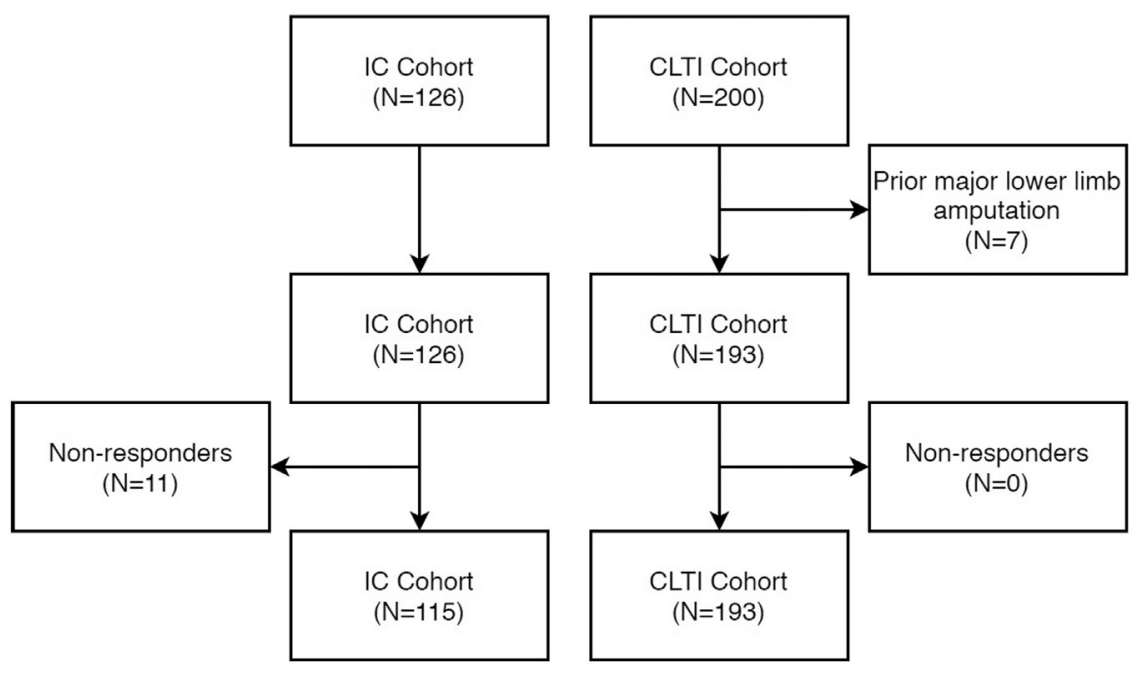

Fig. 1. Flowchart of the intermittent claudication (IC) and chronic limb-threatening ischemia (CLTI) cohorts.

patients had CLTI. In Figure 1, a flowchart is presented, and 11 nonresponders from the IC arm of the study were excluded from data analyses. In Table I, an overview of baseline characteristics and a comparison between the IC and CLTI groups is presented. In general, patients with CLTI were older and had more comorbidities than patients with IC.

A comparison of QOL between the IC and CLTI group is presented in Table II. Patients with IC had a higher QOL in the physical health (mean difference 2.9), psychological health (mean difference 1.2), environment (mean difference 0.8), and the overall domain (mean difference 0.4). Patients with CLTI had a slightly higher QOL in the social relationships domain (mean difference 0.2 ), but this difference was not statistically significant.

After correcting for the confounding effect of age and sex, IC patients still had a statistically significant higher QOL in the physical, psychological, environment, and overall domain (see Table III). The QOL in the social relationships domain was nonsignificantly higher in the CLTI group.

In Table IV, the results of the analyses corrected for age, sex, diabetes, hypertension, renal impairment, cardiac history, pulmonary history, cerebrovascular history, and history of bypass surgery are presented. The psychological and environment domains were no longer statistically significantly different between the 2 groups. The other 4 domains remained statistically significantly different.

The largest differences in QOL between the IC and CLTI group were observed in the physical and psychological domains of QOL (Cohen's d values in Tables III and IV).
The QOL between Fontaine III and Fontaine IV patients did not differ in any domain. This remained after both correcting for age and sex and for comorbidities.

\section{DISCUSSION}

This study compared QOL between patients with IC and patients with CLTI using WHOQOL-BREF questionnaire After adjustments for age and sex, patients with IC had a significantly higher QOL in the physical, psychological, environment, and overall domains than patients with CLTI.

A prior study observed a diminished HS in patients with CLTI in comparison to patients with less severe forms of PAD. ${ }^{11}$ It should be noticed, however, that Sprengers et al. looked at HS. Our study compared the different subdomains of QOL and showed similar results. This is indicating that both objective functioning (HS) and the subjective appraisal of well-being (QOL) is diminished in patients with CLTI compared with patients with IC.

The largest difference in QOL between the 2 patient groups occurred in the physical and the psychological domain. This implicates that physicians should not only be focused on treatments that improve physical health. Instead, they should simultaneously consider treatments that may improve psychological health. As expected, patients with CLTI experience more pain than patients with IC. ${ }^{15}$ Consequently, treatment strategies such as adequate pain management may be effective to increase QOL. 
Table II. WHOQOL-BREF values of both cohorts at baseline

\begin{tabular}{llllrr}
\hline Quality of life domains & IC $(n=115)$ & Missing & CLTI $(n=193)$ & Missing & $P$ value \\
\hline Physical health (SD) & $13.7(2.3)$ & 0 & $10.8(2.8)$ & 3 & $<0.001$ \\
Psychological health (SD) & $15.3(2.1)$ & 0 & $14.1(2.4)$ & 0 & $<0.001$ \\
Social relationships (SD) & $15.3(2.7)$ & 0 & $15.5(2.6)$ & 4 & 0.488 \\
Environment (SD) & $16.3(2.4)$ & 0 & $15.5(2.0)$ & 7 & 0.002 \\
Overall (SD) & $3.5(0.7)$ & 0 & $3.1(0.9)$ & 2 & $<0.001$ \\
\hline
\end{tabular}

${ }^{\mathrm{a} A n}$ independent samples $t$-test was used.

Table III. Analysis of variance analyses of QOL between the IC and CLTI group

\begin{tabular}{|c|c|c|c|c|}
\hline Quality of life domains ${ }^{\mathrm{a}}$ & IC $(n=115)$ & CLTI $(n=193)$ & $P$ value & Cohen's d \\
\hline Physical health $(95 \% \text { CI })^{b}$ & $13.5(12.9-14)$ & $10.7(10.3-11)$ & $<0.001$ & $1.01(0.76-1.26)$ \\
\hline Psychological health $(95 \% \mathrm{CI})^{\mathrm{b}}$ & $15.5(15-15.9)$ & $14(13.7-14.4)$ & $<0.001$ & $0.64(0.40-0.88)$ \\
\hline Social relationships $(95 \% \mathrm{CI})^{\mathrm{b}}$ & $15(14.4-15.6)$ & $15.4(15-15.8)$ & 0.002 & $-0.15(-0.38$ to -0.09$)$ \\
\hline Environment $(95 \% \mathrm{CI})^{\mathrm{b}}$ & $16.3(15.9-16.8)$ & $15.6(15.2-15.9)$ & 0.005 & $0.32(0.08-0.55)$ \\
\hline Overall $(95 \% \mathrm{CI})^{\mathrm{b}}$ & $3.4(3.3-3.6)$ & $3.0(2.9-3.2)$ & 0.004 & $0.48(0.24-0.72)$ \\
\hline
\end{tabular}

${ }^{a}$ Covariates age and sex were added to the model as possible confounders.

${ }^{\mathrm{b}}$ Outcomes are expressed as estimated marginal means.

The results may also indicate that QOL deteriorates when patients progress from IC to CLTI. With the study outcomes, patients may now be educated on the decrease in QOL that is associated with the progression of IC to CLTI. This may increase, a patients' awareness and intrinsic motivation to initiate lifestyle modifications.

Simultaneously, it underlines the importance of a SET program for patients with IC. In the Netherlands, patients are accompanied by a therapist trained in motivational interviewing during the program. The multicomponent program is not only aimed to increase the maximal walking distance but also focusses on intrinsic motivation and initiating lifestyle modifications. These lifestyle modifications, such as smoking cessation and exercise therapy, have been shown to be beneficial for patients with IC. ${ }^{16-18}$ Another effect such as the use of statins effectively reduces disease progression and enhances walking distance and may enhance QOL. ${ }^{19}$ Nevertheless, studies about the effect of lifestyle modifications and pharmacotherapy on QOL in patients with PAD are scarce. Future research should investigate the effect of lifestyle interventions on QOL as they may have a beneficial effect.

It should be noted that no statistically significant difference between the IC and CLTI group in the psychological and environment domain remained after several covariates were added to the model (Table IV). Hence, the differences in the psychological and environment QOL domains between the 2 groups that were observed in this study are largely explained by differences in preexistent comorbidities. Simultaneously, this reveals a negative effect of comorbidities on psychological QOL in both the IC and CLTI cohort. Physicians should be aware of this as psychological interventions may enhance QOL-related outcomes. ${ }^{20}$ The physical, social relationships, and overall domain were not altered by adding comorbidities as confounders to the model. Apparently, the differences in the other QOL domains are explained by other factors than comorbidities alone.

The social relationships QOL domain was the only QOL domain that was in favor of the CLTI group, after correcting for age, sex, and comorbidities. In contrast to the other QOL domains, it seems that social relationships are not negatively affected by disease progression. Hypothetically, the increased need for personal care enables patients with CLTI to interact with different individuals. Thus, social relationships may be more easily maintained in patients with CLTI.

The minimal clinically important difference (MCID) for the WHOQOL-BREF in patients with PAD has not been studied. In a study cohort that consisted of patients with lung cancer, the MCID ranged from 0.88 to 1.55 , and the MCID for the WHOQOL100 was 1 in a cohort of patients with early stage breast cancer. ${ }^{21,22}$ By extrapolating the MCID of 1 to our study results, the differences in QOL between the IC and CLTI group may be considered clinically relevant. Further research on the MCID of the WHOQOL-BREF in patients with PAD is warranted to add further value to these study results. 
Table IV. Analysis of variance analyses of QOL between the IC and CLTI group

\begin{tabular}{|c|c|c|c|c|}
\hline Quality of life domains ${ }^{a}$ & IC $(n=115)$ & CLTI $(n=193)$ & $P$ value & Cohen's d \\
\hline Physical health $(95 \% \text { CI })^{\mathrm{b}}$ & $13.2(12.6-13.8)$ & $10.8(10.4-11.2)$ & $<0.001$ & $0.83(0.58-1.08)$ \\
\hline Psychological health $(95 \% \mathrm{CI})^{\mathrm{b}}$ & $15(14.5-15.5)$ & $14.1(13.8-14.5)$ & 0.066 & $0.35(0.11-0.59)$ \\
\hline Social relationships $(95 \% \mathrm{CI})^{\mathrm{b}}$ & $14.9(14.3-15.5)$ & $15.4(15-15.8)$ & 0.004 & $-0.17(-0.41$ to -0.06$)$ \\
\hline Environment $(95 \% \mathrm{CI})^{\mathrm{b}}$ & $16.1(15.6-16.6)$ & $15.6(15.3-15.9)$ & 0.16 & $0.21(-0.03$ to 0.45$)$ \\
\hline Overall $(95 \% \mathrm{CI})^{\mathrm{b}}$ & $3.4(3.2-3.5)$ & $3.1(3-3.2)$ & 0.009 & $0.34(0.10-0.58)$ \\
\hline
\end{tabular}

${ }^{a}$ Covariates age, sex, diabetes, hypertension, renal impairment, cardiac history, pulmonary history, cerebrovascular history, and history of bypass surgery were added to the model as possible confounders.

${ }^{\mathrm{b}}$ Outcomes are expressed as estimated marginal means.

PROMs are gaining popularity in contemporary literature. Most PROMs merely focus on asking patients about objective outcomes (HS) and do not take the patient's evaluation (satisfaction) of QOL into account. ${ }^{23,24}$ The WHOQOL-BREF measures a patient's QOL and is represented in 5 domains. In essence, it enables physicians to specifically target the domains of QOL that are most susceptible for improvement. We, therefore, argue that the WHOQOL-BREF is the most suitable PROM to be used to determine treatment strategies. Future studies examining QOL should include the WHOQOL-BREF as the main outcome measure if one wants to assess QOL and not, for example, HS. $^{23,24}$

\section{LIMITATIONS}

Because this study cohort consisted of 2 separate cohorts, no direct statements about the causative effect of IC or CLTI on QOL can be made based on this study. Nevertheless, this study provided insight into the differences in QOL at baseline between the 2 groups. Furthermore, both cohorts contain patient populations from similar regional hospitals in the Netherlands, in similar time-periods (with similar treatment options).

\section{CONCLUSION}

Patients with IC have a significantly higher QOL in the physical, psychological, environment, and overall domains compared with patients with CLTI, even after correcting for age and sex. This underlines the importance of strategies that reduce disease progression as disease progression is associated with a decrease in QOL.

None.

\section{REFERENCES}

1. WHO. WHOQOL: Measuring Quality of Life, https://Www. who.int/healthinfo/survey/whoqol-qualityoflife/en/; 2019. Accessed August 4, 2019.

2. Wu A, Coresh J, Selvin E, et al. Lower extremity peripheral artery disease and quality of life among older individuals in the community. J Am Heart Assoc 2017;6:e004519.

3. van den Houten MM, Gommans LN, van der Wees PJ, et al. Minimally important difference of the absolute and functional claudication distance in patients with intermittent claudication. Eur J Vasc Endovasc Surg 2016;51: 404-9.

4. Patterson RB, Pinto B, Marcus B, et al. Value of a supervised exercise program for the therapy of arterial claudication. $\mathrm{J}$ Vasc Surg 1997;25:312-8.

5. Regensteiner JG, Steiner JF, Hiatt WR. Exercise training improves functional status in patients with peripheral arterial disease. J Vasc Surg 1996;23:104-15.

6. Morris-Stiff G, Lewis MH. Gabapentin (Neurontin) improves pain scores of patients with critical limb ischaemia: an observational study. Int J Surg 2010;8:212-5.

7. Conte MS, Bradbury AW, Kolh P, et al. Global vascular guidelines on the management of chronic limb-threatening ischemia. J Vasc Surg 2019;69:3S-125S.e40.

8. Development of the World health organization WHOQOLBREF quality of life assessment. The WHOQOL group. Psychol Med 1998;28:551-8.

9. Alabi O, Roos M, Landry G, et al. Quality-of-life assessment as an outcomes measure in critical limb ischemia. J Vasc Surg 2017;65:571-8.

10. Steunenberg SL, de Vries J, Raats JW, et al. Quality of life and mortality after endovascular, surgical, or conservative treatment of elderly patients suffering from critical limb ischemia. Ann Vasc Surg 2018;51:95-105.

11. Sprengers RW, Teraa M, Moll FL, et al. Quality of life in patients with no-option critical limb ischemia underlines the need for new effective treatment. J Vasc Surg 2010;52: 843-9.

12. Breek JC, Hamming JF, De Vries J, et al. Quality of life in patients with intermittent claudication using the World Health Organisation (WHO) questionnaire. Eur J Vasc Endovasc Surg 2001;21:118-22.

13. Pell JP. Impact of intermittent claudication on quality of life. The scottish vascular audit group. Eur J Vasc Endovasc Surg 1995;9:469-72.

14. van den Houten MM, Jansen SC, Sinnige A, et al. Protocol for a prospective, longitudinal cohort study on the effect of arterial disease level on the outcomes of supervised exercise in intermittent claudication: the ELECT Registry. BMJ Open 2019;9:e025419. 
15. Klevsgard R, Hallberg IR, Risberg B, et al. Quality of life associated with varying degrees of chronic lower limb ischaemia: comparison with a healthy sample. Eur J Vasc Endovasc Surg 1999;17:319-25.

16. Quick CR, Cotton LT. The measured effect of stopping smoking on intermittent claudication. Br J Surg 1982;69(Suppl):S24-6.

17. Jonason $\mathrm{T}$, Bergstrom R. Cessation of smoking in patients with intermittent claudication. Effects on the risk of peripheral vascular complications, myocardial infarction and mortality. Acta Med Scand 1987;221:253-60.

18. Lane R, Harwood A, Watson L, et al. Exercise for intermittent claudication. Cochrane Database Syst Rev 2017;12:Cd000990.

19. Aung PP, Maxwell HG, Jepson RG, et al. Lipid-lowering for peripheral arterial disease of the lower limb. Cochrane Database Syst Rev 2007;2007:Cd000123.

20. Anderson N, Ozakinci G. Effectiveness of psychological interventions to improve quality of life in people with long- term conditions: rapid systematic review of randomised controlled trials. BMC Psychol 2018;6:11.

21. de Mol M, Visser S, Aerts J, et al. Satisfactory results of a psychometric analysis and calculation of minimal clinically important differences of the World Health Organization quality of life-BREF questionnaire in an observational cohort study with lung cancer and mesothelioma patients. BMC Cancer 2018;18:1173.

22. Den Oudsten BL, Van Heck GL, Van der Steeg AF, et al. The WHOQOL-100 has good psychometric properties in breast cancer patients. J Clin Epidemiol 2009;62:195-205.

23. Herdman M, Gudex C, Lloyd A, et al. Development and preliminary testing of the new five-level version of EQ-5D (EQ5D-5L). Qual Life Res 2011;20:1727-36.

24. Ware JE Jr, Sherbourne CD. The MOS 36-item short-form health survey (SF-36). I. Conceptual framework and item selection. Med Care 1992;30:473-83. 